\title{
Gamma-glutamyl-transferase may predict COVID-19 outcomes in hospitalized patients
}

\author{
Ahmet Yozgat ${ }^{1}$, benan kasapoglu ${ }^{2}$, Alpaslan Tanoğlu ${ }^{3}$, Güray Can ${ }^{4}$, Yusuf Serdar Sakin ${ }^{5}$, \\ and Murat Kekilli ${ }^{6}$ \\ ${ }^{1}$ Ufuk Üniversitesi Tip Fakültesi \\ ${ }^{2}$ Lokman Hekim University \\ ${ }^{3}$ Sancaktepe Şehit Prof Dr Ilhan Varank Training and Research Hospital \\ ${ }^{4}$ Affiliation not available \\ ${ }^{5}$ Ankara Gulhane Egitim ve Arastirma Hastanesi \\ ${ }^{6}$ Gazi University
}

August 19, 2021

\begin{abstract}
Aim: In this study, we aimed to define the predictive role of liver function tests at admission to the hospital in outcomes of hospitalized patients with COVID-19. Material and Method: In this multicentric retrospective study, a total of 269 adult patients ([?]18 years of age) with confirmed COVID-19 who were hospitalized for the treatment were enrolled. Demographic features, complete medical history, and laboratory findings of the study participants at admission were obtained from the medical records. Patients were grouped regarding their ICU requirements during their hospitalization periods. Results: Among all 269 participants, 106 were hospitalized in the intensive care unit (ICU) and 66 died. The patients hospitalized in ICU were older than patients hospitalized in wards $(\mathrm{p}=0.001)$ and expired patients were older than alive patients $(\mathrm{p}=0.001)$. Age, elevated serum D-dimer, creatinine, and gamma-glutamyl transferase (GGT) levels at admission were independent factors predicting ICU hospitalization and mortality in COVID-19 patients. Conclusion: In conclusion, in hospitalized patients with COVID-19, laboratory data on admission, including serum, creatinine, GGT and d-dimer levels have an important predictive role for the ICU requirement and mortality. Since these tests are readily available in all hospitals and inexpensive, some predictive formulas may be calculated with these parameters at admission, to define the patients requiring intensive care.
\end{abstract}

\section{INTRODUCTION}

Coronavirus disease 2019 (COVID-19) is an acute respiratory infectious disease caused by severe acute respiratory syndrome coronavirus $2(\mathrm{SARS}-\mathrm{CoV}-2)^{1,2}$. Since the patients can suddenly get worsen requiring intensive care unit (ICU), early identification and timely intervention of patients with a tendency to become severe is essential to improve outcomes ${ }^{1}$.

Liver function tests (LFTs) including aspartate aminotransferase (AST), alanine aminotransferase (ALT), gamma-glutamyl transferase (GGT), alkaline phosphatase (ALP), and bilirubin levels are studied in COVID19 in some previous studies ${ }^{3,4}$. As with many viral infections, Severe acute respiratory syndrome coronavirus 2 (SARS-CoV-2) is also shown to be associated with abnormal liver function tests ${ }^{5}$.

Angiotensin-converting enzyme 2 (ACE2) is known to be the host cell receptor for SARS-CoV-2. It has been shown that there is a significant enrichment of ACE2 expression in a major portion of the cholangiocyte clusters. GGT is a diagnostic biomarker for cholangiocyte injury and thus may be suggested as a marker 
of cholangiocyte involvement in COVID-19 ${ }^{6,7}$. Patients with elevated liver function tests were related to more severe disease in COVID- $19^{8,9}$.

In this study, we aimed to define the predictive role of liver function tests at admission to the hospital in outcomes of hospitalized patients with Covid-19. In this way, we aimed to define an effective tool for the early clinical detection of severe cases in the COVID-19 outbreak.

\section{MATERIAL AND METHODS}

In this multicentric retrospective study, adult patients ([?]18 years of age) with confirmed COVID-19 who were hospitalized for the treatment were enrolled. The study was approved by the local ethics committee of Lokman Hekim University with the number of 2021/065. Informed consent was obtained from all of the patients.

Diagnosis of COVID-19 was assessed by using nasopharyngeal swap reverse transcriptase-polymerase chain reaction (Real-Time PCR) according to WHO guideline ${ }^{10}$. Patients were treated in line with the recommendations of Turkey's Health Ministry COVID-19 adult patient treatment guidelines ${ }^{11}$. Demographic features, complete medical history, and laboratory findings of the study participants at admission are obtained from the hospital records. The laboratory data including hemoglobin level, white blood cell count, neutrophil and lymphocyte counts, ALT, AST, GGT, and ALP levels, serum creatinine level, concentrations of D-dimer, and C-reactive protein (CRP) levels were recorded. All data were obtained at the admission of the patients before treatment.

Patients with missing data, having any known chronic hepatobiliary diseases, non-alcoholic fatty liver disease, patients with alcohol abuse, hepatobiliary malignancies and receiving drugs known to have cholestatic effects other than those used in COVID-19 management, end-stage renal disease and patients on hemodialysis were excluded from the study. 483 patients were evaluated and it was decided to include 269 patients due to strict exclusion criteria.

Patients were grouped regarding their ICU requirements during their hospitalization periods. Moreover, the outcomes of the patients at the end of the treatment were also recorded. Patients whose treatment or hospitalization periods were continuing during the data collection were not included in the study.

\section{Statistical analysis}

Statistical analyses were performed using SPSS 20.0 software. Categorical variables were described as frequency rates and percentages, and continuous variables were described using mean values. Mean values for continuous variables were compared using independent group t-tests when the data were normally distributed. Multivariate logistic regression analysis was performed to calculate adjusted odds ratios (OR) with its $95 \%$ confidence interval (CI) for ICU hospitalization and mortality in COVID-19 patients. ROC curves were obtained for the parameters that were significsntly affecting mortality. $P<0.05$ was considered statistically significant.

\section{RESULTS}

Totally 269 patients (95 female and 174 male) hospitalized for COVID-19 were included in the study. Among participants, 106 were hospitalized in the intensive care unit and 66 of them died. Demographic features of study participants are summarized in Table 1 . There was not any significant difference between hospitalized patients in ICU or wards and alive or death patients regarding gender. However, patients hospitalized in ICU were older than patients hospitalized in wards (p:0.001); and expired patients were older than alive patients (p:0.001).

Table 1. Demographic features of study participants

\begin{tabular}{lllll}
\hline Hospitalization in ICU & Hospitalization in ICU & Hospitalization in ICU & O \\
\hline Hospitalized in Wards (n:163) & Hospitalized in ICU (n: 106) & $\mathbf{P}^{(1)}$ & A
\end{tabular}




\begin{tabular}{lllll}
\hline & Hospitalization in ICU & Hospitalization in ICU & Hospitalization in ICU & O \\
\hline Gender (F/M) & $56 / 107$ & $39 / 67$ & 0.69 & 68 \\
Age (years) & $49.18 \pm 20.72$ & $68.30 \pm 14.98$ & $\mathbf{0 . 0 0 1}$ & 52 \\
\hline
\end{tabular}

F: Female, M: Male, ${ }^{1}$ Chi Square and Independent Sample T-test; ICU: Intensive Care Unit

Laboratory data of study participants are summarized in Table 2. Hemoglobin, white blood cell count, liver and renal function tests, D-dimer, and CRP levels of study participants are summarized in Table 2. While AST, GGT, white blood cell count, creatinine, D-Dimer and CRP levels were significantly higher in patients hospitalized in intensive care units than in patients hospitalized in wards, Hb levels were significantly lower. These laboratory parameters showed similar changes in expired patients compared to survivors.

Table 2. Laboratory data of study participants

\begin{tabular}{|c|c|c|c|c|c|c|}
\hline & $\begin{array}{l}\text { Hospitalization } \\
\text { in ICU }\end{array}$ & $\begin{array}{l}\text { Hospitalization } \\
\text { in ICU }\end{array}$ & $\begin{array}{l}\text { Hospitalization } \\
\text { in ICU }\end{array}$ & Outcomes & Outcomes & Outcomes \\
\hline & $\begin{array}{l}\text { Hospitalized } \\
\text { in Wards } \\
(\mathrm{n}: 163)\end{array}$ & $\begin{array}{l}\text { Hospitalized } \\
\text { in ICU (n: } \\
106)\end{array}$ & $\mathbf{P}^{(1)}$ & $\begin{array}{l}\text { Alive } \\
(\mathrm{n}: 203)\end{array}$ & $\begin{array}{l}\text { Death } \\
(\mathrm{n}: 66)\end{array}$ & $p^{(1)}$ \\
\hline Hemoglobin & $13.38 \pm 1.99$ & $11.96 \pm 2.66$ & 0.001 & $13.10 \pm 2.27$ & $11.95 \pm 2.53$ & 0.001 \\
\hline $\begin{array}{l}\text { WBC } \\
\text { count } \\
\left(\times 10^{9} / \mathrm{L}\right)\end{array}$ & $6.71 \pm 2.04$ & $1.01 \pm 5.57$ & 0.001 & $7.17 \pm 3.48$ & $1.09 \pm 6.04$ & 0.001 \\
\hline $\begin{array}{l}\text { Neutrophil } \\
\left(\times 10^{9} / \mathbf{L}\right)\end{array}$ & $4.66 \pm 2.81$ & $8.11 \pm 5.38$ & 0.001 & $5.19 \pm 2.56$ & $8.57 \pm 5.48$ & 0.001 \\
\hline $\begin{array}{l}\text { Lymphocyte } \\
\left(\times 10^{9} / \mathrm{L}\right)\end{array}$ & $1.48 \pm 0.78$ & $1.42 \pm 1.00$ & 0.65 & $1.47 \pm 0.90$ & $1.40 \pm 0.93$ & 0.62 \\
\hline $\begin{array}{l}\mathbf{A L T} \\
(\mathbf{U} / \mathbf{L})\end{array}$ & $30.68 \pm 31.04$ & $46.22 \pm 38.28$ & 0.061 & $31.47 \pm 22.62$ & $53.20 \pm 40.72$ & 0.021 \\
\hline $\operatorname{AST}(\mathbf{U} / \mathbf{L})$ & $26.63 \pm 17.81$ & $81.52 \pm 40.11$ & 0.023 & $30.10 \pm 27.766$ & $104.12 \pm 80.51$ & 0.001 \\
\hline GGT(U/L) & $23.62 \pm 14.98$ & $43.27 \pm 37.075$ & 0.001 & $26.02 \pm 16.431$ & $47.85 \pm 34.24$ & 0.001 \\
\hline $\operatorname{ALP}(\mathbf{U} / \mathbf{L})$ & $70.63 \pm 23.97$ & $74.68 \pm 27.42$ & 0.15 & $72.16 \pm 25.6$ & $79.45 \pm 29.44$ & 0.12 \\
\hline $\begin{array}{l}\text { Creatinine } \\
(\mathrm{mg} / \mathrm{dl})\end{array}$ & $0.95 \pm 0.22$ & $1.30 \pm 0.98$ & 0.001 & $0.97 \pm 0.32$ & $1.45 \pm 1.14$ & 0.001 \\
\hline $\begin{array}{l}\text { D-dimer } \\
(\mathrm{ng} / \mathrm{ml})\end{array}$ & $1823.33 \pm 1020.73$ & $3722.52 \pm 1236.17$ & 0.001 & $1762.41 \pm 975.53$ & $4943.288 \pm 1191$ & 60.001 \\
\hline $\operatorname{CRP}(\mathbf{m g} / \mathrm{L})$ & $44.22 \pm 31.77$ & $110.589 \pm 88.50$ & 0.001 & $51.95 \pm 43.43$ & $127.03 \pm 98.45$ & 0.001 \\
\hline
\end{tabular}

${ }^{1}$ Independent sample T-test; WBC: White blood cell; ALT: Alanine aminotransferase; AST: Aspartate aminotransferase; GGT: Gamma-glutamyl-transferase; ALP:Alkaline phosphatase; CRP: C-Reactive protein; ICU: Intensive Care Unit

Risk factors associated with the ICU hospitalization and mortality in COVID-19 patients were analyzed with the logistic regression analysis (Table 3). Regarding these findings, age ( $>65)$ (p:0.001, OR:4.05), elevated serum d-dimer $(>500)$ (p:0.001, OR:4.046), creatinine $(>1,1)$ (p:0.023, OR:2.165) and GGT levels $(>40)$ (p:0015, OR:2.374) at admission were independent factors predicting mortality in COVID-19 patients.

Table 3. Risk factors associated with the ICU hospitalization and mortality in COVID-19 


\begin{tabular}{|c|c|c|c|c|}
\hline & $\begin{array}{l}\text { ICU } \\
\text { hospitalization }\end{array}$ & $\begin{array}{l}\text { ICU } \\
\text { hospitalization }\end{array}$ & Mortality & Mortality \\
\hline & OR $(95 \% \mathrm{CI})$ & $p^{(1)}$ & OR $(95 \% \mathrm{CI})$ & $p^{(1)}$ \\
\hline Age $(>65)$ & $3.27(1.64-6.61)$ & 0.001 & $\begin{array}{l}4.050 \\
(1.918-8.551)\end{array}$ & 0.001 \\
\hline $\begin{array}{l}\text { Hemoglobin } \\
(<\mathbf{1 2})\end{array}$ & $\begin{array}{l}0.867(0.434 \\
-1.729)\end{array}$ & 0.685 & $\begin{array}{l}1.089 \\
(0.539-2.199)\end{array}$ & 0.813 \\
\hline $\begin{array}{l}\text { WBC count } \\
\left(>9 \times 10^{9} / L\right)\end{array}$ & $0.82(0.68-1.29)$ & 0.207 & $\begin{array}{l}2.280 \\
(1.156-4.496)\end{array}$ & 0.017 \\
\hline $\mathbf{A S T}(>35 \mathrm{U} / \mathbf{L})$ & $\begin{array}{l}0.641 \\
(0.297-1.383)\end{array}$ & 0.257 & $1.036(.478-2.248)$ & 0.928 \\
\hline $\begin{array}{l}\operatorname{GGT}(>40 \\
\mathrm{U} / \mathbf{L})\end{array}$ & $2.731(1.26-5.90)$ & 0.011 & $2.374(1.23-4.48)$ & 0.015 \\
\hline $\begin{array}{l}\text { Creatinine } \\
(\mathrm{mg} / \mathrm{dl})(>1.1)\end{array}$ & $2.19(1.11-4.29)$ & 0.022 & $2.165(1.115-4.206)$ & 0.023 \\
\hline $\begin{array}{l}\text { D-dimer } \\
(\mathrm{ng} / \mathrm{ml})(>500)\end{array}$ & $3.84(1.94-7.57)$ & 0.001 & $4.046(1.821-8.989)$ & 0.001 \\
\hline $\begin{array}{l}\text { CRP } \\
(\mathrm{mg} / \mathrm{L})(>10)\end{array}$ & $3.95(1.52-10.17)$ & 0.004 & $1.273(.690-2.645)$ & 0.205 \\
\hline
\end{tabular}

(1) Multivariate logistic regression analysis; WBC: White blood cell; AST: Aspartate aminotransferase; GGT: Gamma-glutamyl-transferase; CRP: C-Reactive protein; ICU:Intensive Care Unit; OR:Odds-ratio

In ROC curve analysis, the areas under the curve were calculated for these variables and summarized in Table 4.

Table 4. The results of ROC curve analyses

\begin{tabular}{llll}
\hline & AUC & Asymptotic 95\% Confidence Interval & Asymptotic 95\% Confidence Interval \\
\hline & & Lower Bound & Upper Bound \\
Age & 0.728 & 0.703 & 0.807 \\
GGT & 0.759 & 0.69 & 0.827 \\
Creatinine & 0.698 & 0.615 & 0.782 \\
CRP & 0.758 & 0.692 & 0.824 \\
\hline
\end{tabular}

GGT: Gamma-glutamyl-transferase; CRP: C-Reactive protein 


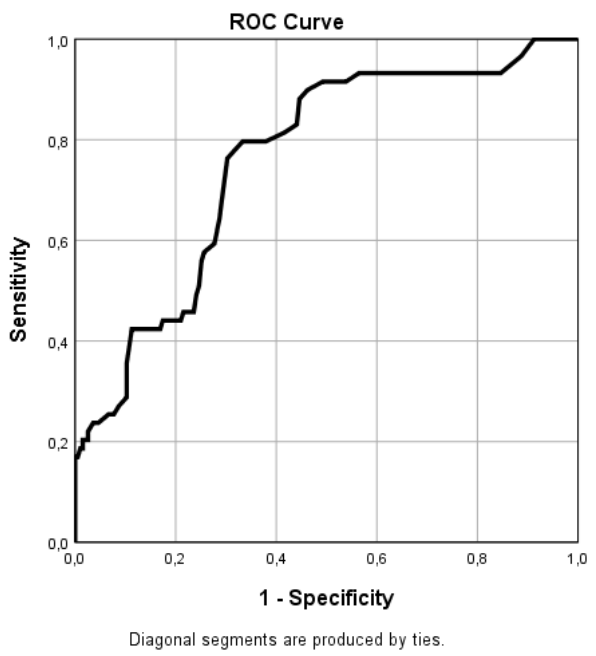

Figure 1. ROC curve for GGT in prediction of mortality

Since the AUC was the highest for GGT, we calculated some GGT values to predict the mortality in ROC curve with different sensitivity and specificity values. Regarding these results, $30.5 \mathrm{U} / 1$ has the best sensitivity $(76.3 \%)$ and specificity $(69.7 \%)$ combination.

\section{DISCUSSION}

In this study, we analyzed the factors affecting ICU hospitalization and mortality in patients with Covid-19 and we determined that age older than 65 years, higher serum D-dimer, creatinine, and GGT levels than the upper limits of the laboratory at admission were independent factors predicting ICU hospitalization and mortality in COVID-19 patients. Moreover, in ROC analysis, we determined that GGT values higher than $30 \mathrm{U} / \mathrm{l}$ at admission should be regarded as a risk factor for mortality and these patients should be evaluated more intensely.

Since an early identification and timely intervention of patients with a tendency to become severe is essential to improve outcomes in COVID -19 patients, there are many studies in previous literature evaluating the predictive factors of outcomes. Jinrui et al. reported that the higher level of CRP and ALT levels and chronic comorbidities were the risk factors for the progression into severe pneumonia in COVID-19 patients ${ }^{12}$. Ullah et al. defined elevated CRP and D-dimer levels as independent predictors of in-hospital mortality ${ }^{13}$. Supporting our results, in a meta-analysis, age, and CRP levels were also defined as the main risk factors in predicting severe COVID-19 outcomes ${ }^{14}$. Unlike this study, in our study, it was determined that GGT is important in predicting the outcome. Our strict exclusion criteria and the fact that the study was conducted in a larger population may explain this difference between these two studies.

Based on the admission data, in elderly patients, serum albumin and D-dimer levels and onset to hospitalization time were reported as significant predictors for the severity of COVID-19 ${ }^{15}$. In another meta-analysis performed to identify the predictors associated with poor clinical outcomes in patients with COVID-19, severe COVID-19 was associated with lower levels of lymphocytes and hemoglobin; elevated levels of ALT, AST, creatinine, high-sensitivity CRP, D-dimer, ferritin, and LDH levels ${ }^{16}$. Our results were supporting these previous findings and we also determined that older age and elevated serum d-dimer, creatinine, and GGT levels at admission were independent factors predicting ICU hospitalization and mortality in COVID19 patients. Admission serum CRP levels were associated with the ICU hospitalization but not with the mortality in our study. This may be associated with the late elevation of CRP levels requiring time for the synthesis during the hospitalization of patients.

In previous literature, patients with elevated liver function tests were related to more severe disease in 
COVID-19 ${ }^{8,9}$. However, Ramachandran et al. reported that elevated AST or ALT levels among hospitalized COVID-19 patients were associated with higher rates of mechanical ventilation but were not a significant independent predictor of more severe disease ${ }^{17}$. In a recent study from Turkey, elevated serum ALT, AST levels, and AST/ALT ratio $>1$ were associated with the more severe course and increased mortality in COVID-19 ${ }^{18}$. However, Ponziani et al. reported that baseline liver test abnormalities were associated with the increased risk of ICU admission but not the outcomes ${ }^{19}$. Similarly, Monterde et al. reported that abnormalities in liver function tests on admission were not associated with survival but with respiratory complications at admission. However, an increase during hospitalization in GGT, and ALP levels was associated with reduced survival ${ }^{20}$. On the other hand, Zhang et al did not determine any role of ALT, AST, or GGT levels in predicting severe COVID-19 infection ${ }^{21}$.

In a clinical epidemiological study, Shao et al reported that elevated GGT and CRP levels were associated with a longer length of hospital stay ${ }^{22}$. Very recently, abnormal liver biochemical tests at admission were reported to be closely related to the severity and prognosis of COVID-19 patients, supporting our findings ${ }^{23}$. In this study, we determined that elevated serum GGT levels, but not aminotransferases, at admission were associated with the increased risk for ICU hospitalization and mortality.

There are some limitations to this study that should be mentioned. First, this is a retrospective study carrying some bias of this type of investigation. Secondly, we did not analyze the effects of comorbidities in this group of patients, which may also affect the outcomes. Although we could not exclude all factors that may cause GGT elevation in participants, multicentered design of study and using same treatment algorithms were the strong ways of this current research.

In conclusion, in hospitalized patients with COVID-19, laboratory data on admission, including serum GGT, creatine, and d-dimer levels have an important predictive role for the ICU requirement and mortality. Since these tests are readily available in all hospitals and inexpensive, some predictive formulas may be calculated with these parameters at admission, to define the patients requiring more intense treatments.

Conflict of interest : None

\section{RFERENCES}

1. Mannucci E, Silverii A, Monami M. Association between different screening strategies for SARS-CoV-2 and deaths and severe disease in Italy. International journal of clinical practice. Nov 24 2020:e13867. doi:10.1111/ijcp.13867

2. Ozcelik F, Tanoglu A, Guven BB, Keskin U, Kaplan M. Assessment of severity and mortality of COVID19 with anti-A1 and B IgM isohemagglutinins, a reflection of the innate immune status.International journal of clinical practice. Jul 12 2021:e14624. doi:10.1111/ijcp.14624

3. Richardson S, Hirsch JS, Narasimhan M, et al. Presenting Characteristics, Comorbidities, and Outcomes Among 5700 Patients Hospitalized With COVID-19 in the New York City Area. Jama . May 26 2020;323(20):2052-2059. doi:10.1001/jama.2020.6775

4. Guan WJ, Ni ZY, Hu Y, et al. Clinical Characteristics of Coronavirus Disease 2019 in China. The New England journal of medicine. Apr 30 2020;382(18):1708-1720. doi:10.1056/NEJMoa2002032

5. Bertolini A, van de Peppel IP, Bodewes F, et al. Abnormal Liver Function Tests in Patients With COVID19: Relevance and Potential Pathogenesis. Hepatology . Nov 2020;72(5):1864-1872. doi:10.1002/hep.31480

6. Li W, Moore MJ, Vasilieva N, et al. Angiotensin-converting enzyme 2 is a functional receptor for the SARS coronavirus. Nature . Nov 27 2003;426(6965):450-4. doi:10.1038/nature02145

7. Hoffmann M, Kleine-Weber H, Schroeder S, et al. SARS-CoV-2 Cell Entry Depends on ACE2 and TMPRSS2 and Is Blocked by a Clinically Proven Protease Inhibitor. Cell . Apr 16 2020;181(2):271-280 e8. doi:10.1016/j.cell.2020.02.052 
8. Ali N, Hossain K. Liver injury in severe COVID-19 infection: current insights and challenges. Expert review of gastroenterology \& hepatology . Oct 2020;14(10):879-884. doi:10.1080/17474124.2020.1794812

9. Yang R, Gui X, Ke H, Gao S, Luo M, Xiong Y. The indicative role of markers for liver injury on the severity and prognosis of coronavirus disease 2019 patients. European journal of gastroenterology 83 hepatology . Oct 29 2020;doi:10.1097/MEG.0000000000001968

10. Organization WH. Assessment tool for laboratories implementing COVID-19 virus testing: interim guidance, 8 April 2020.https://apps.who.int/iris/handle/10665/331714

11. Bakanligi TCS. COVID-19 (SARS-CoV-2 ENFEKSIYONU) ERIŞKİN HASTA TEDAVISİ. October 2020.https://covid19.saglik.gov.tr/TR-66926/eriskin-hasta-tedavisi.html

12. Gao J, Huang X, Gu H, Lou L, Xu Z. Predictive criteria of severe cases in COVID-19 patients of early stage: A retrospective observational study. Journal of clinical laboratory analysis . Oct 2020;34(10):e23562. doi: $10.1002 /$ jcla. 23562

13. Ullah W, Thalambedu N, Haq S, et al. Predictability of CRP and D-Dimer levels for in-hospital outcomes and mortality of COVID-19. Journal of community hospital internal medicine perspectives. Sep 3 2020;10(5):402-408. doi:10.1080/20009666.2020.1798141

14. Katzenschlager S, Zimmer AJ, Gottschalk C, et al. Can we predict the severe course of COVID-19 a systematic review and meta-analysis of indicators of clinical outcome? medRxiv : the preprint server for health sciences . Nov 12 2020;doi:10.1101/2020.11.09.20228858

15. Zeng F, Deng G, Cui Y, et al. A predictive model for the severity of COVID-19 in elderly patients. Aging . Nov 10 2020;12(21):20982-20996. doi:10.18632/aging.103980

16. Mudatsir M, Fajar JK, Wulandari L, et al. Predictors of COVID-19 severity: a systematic review and meta-analysis. F1000Research . 2020;9:1107. doi:10.12688/f1000research.26186.1

17. Ramachandran P, Perisetti A, Gajendran M, Chakraborti A, Narh JT, Goyal H. Increased Serum Aminotransferase Activity and Clinical Outcomes in Coronavirus Disease 2019. Journal of clinical and experimental hepatology . Nov-Dec 2020;10(6):533-539. doi:10.1016/j.jceh.2020.06.009

18. Medetalibeyoglu A, Catma Y, Senkal N, et al. The effect of liver test abnormalities on the prognosis of COVID-19. Annals of hepatology . Nov - Dec 2020;19(6):614-621. doi:10.1016/j.aohep.2020.08.068

19. Ponziani FR, Del Zompo F, Nesci A, et al. Liver involvement is not associated with mortality: results from a large cohort of SARS-CoV-2-positive patients. Alimentary pharmacology $\&$ therapeutics . Sep 2020;52(6):1060-1068. doi:10.1111/apt.15996

20. Bernal-Monterde V, Casas-Deza D, Letona-Gimenez L, et al. SARS-CoV-2 Infection Induces a Dual Response in Liver Function Tests: Association with Mortality during Hospitalization. Biomedicines . Sep 4 2020;8(9)doi:10.3390/biomedicines8090328

21. Zhang Y, Zheng L, Liu L, Zhao M, Xiao J, Zhao Q. Liver impairment in COVID-19 patients: A retrospective analysis of 115 cases from a single centre in Wuhan city, China. Liver Int . Sep 2020;40(9):20952103. doi:10.1111/liv.14455

22. Shao T, Tong Y, Lu S, et al. gamma-Glutamyltransferase Elevations Are Frequent in Patients With COVID-19: A Clinical Epidemiologic Study.Hepatology communications . Jul 11 2020;doi:10.1002/hep4.1576

23. Wu Y, Li H, Guo X, et al. Incidence, risk factors, and prognosis of abnormal liver biochemical tests in COVID-19 patients: a systematic review and meta-analysis. Hepatology international . Sep 2020;14(5):621637. doi:10.1007/s12072-020-10074-6 